\title{
In vitro Assay for Bacterial Membrane Protein Integration into Proteoliposomes
}

Hanako Nishikawa ${ }^{1}$, Masaru Sasaki ${ }^{1}$ and Ken-ichi Nishiyama ${ }^{1,2, *}$

${ }^{1}$ The United Graduate School of Agricultural Sciences, Iwate University, Morioka, Japan; ${ }^{2}$ Department of Biological Chemistry and Food Sciences, Faculty of Agriculture, Iwate University, Morioka, Japan

*For correspondence: nishiyam@iwate-u.ac.jp

[Abstract] It is important to experimentally determine how membrane proteins are integrated into biomembranes to unveil the roles of the integration factors, and to understand the functions and structures of membrane proteins. We have developed a reconstitution system for membrane protein integration in E. coli using purified factors, in which the integration reaction in vivo is highly reproducible. This system enabled not only analysis of membrane-embedded factors including glycolipid MPlase, but also elucidation of the detailed mechanisms underlying membrane protein integration. Using the system, the integration of membrane proteins can be evaluated in vitro through a protease-protection assay. We report here how to prepare (proteo)liposomes and to determine the activities of membrane protein integration.

Keywords: Membrane protein integration, SecYEG, YidC, MPlase, SRP, Diacylglycerol, Proteoliposomes

[Background] Membrane proteins and presecretory proteins, synthesized in the cytosol, are integrated into and translocated across biomembranes, respectively, to be localized at their destinations and to express their functions. Cells possess systems to integrate membrane proteins into and translocate presecretory proteins across biomembranes, these proteins being commonly conserved from bacteria to higher eukaryotes.

In E. coli, a model organism, some integration factors were identified through genetic approaches, these factors including translocon SecYEG (Newitt and Bernstein, 1998), and signal recognition particle (SRP) and its receptor SR (Ulbrandt et al., 1997), and membrane protein insertase/chaperone YidC (Samuelson et al., 2000). These genetic studies were complemented by biochemical approaches. The molecular mechanisms underlying membrane protein integration have been studied extensively using an in vitro system, in which the protein integration reactions were reproduced in test tubes.

Inverted membrane vesicles (INV) can be prepared by disrupting E. coli cells with a French press, followed by sucrose gradients (Alami et al., 2002). The outside surface of INV corresponds to the cytoplasmic face of the inner membrane. Therefore, presecretory proteins are translocated into the lumen of INV. Membrane proteins, synthesized outside of INV using the cell-free translation system, are integrated into INV. The roles of the above-mentioned factors have been analyzed using INV prepared from the respective mutant cells (Koch et al., 1999; Koch and Muller, 2000). However, since most of the factors are essential for cell growth, depletion of each of the factors causes unexpected pleiotropic effects. To exclude such secondary effects, a reconstitution system has been developed using purified 
factors. Proteoliposomes can be prepared by mixing membrane proteins, solubilized and purified in a detergent solution, and phospholipids, followed by removal of the detergent. The reconstituted proteoliposomes are essentially the same as INV and thus they can be directly used in the integration assay in vitro. On the other hand, disordered spontaneous integration of membrane proteins into liposomes formed of phospholipids is a serious problem, since such spontaneous integration is an in vitro artefact that does not reflect the reaction in vivo. We have solved this problem by introducing diacylglycerol (DAG) into the liposomes (Nishiyama et al., 2006; Kawashima et al., 2008). As a consequence, DAG blocked spontaneous integration at the physiological content, which enabled reconstitution of membrane protein integration. By using such a reconstitution system we identified a glycolipid named MPlase (Membrane Protein Integrase) as an essential factor for membrane protein integration (Nishiyama et al., 2006; Nishiyama et al., 2010). Based on the observation that MPlase catalyzes membrane protein integration (Nishiyama et al., 2010), we proposed that MPlase is a "glycolipozyme" (Nishiyama et al., 2012). We also determined the MPlase structure, in which a glycan chain composed of 9 11 repeats of a unit of three $N$-acetylated amino sugars, GlcNAc, ManNAcA and Fuc4NAc, is connected to DAG through a pyrophosphate linker (Nishiyama et al., 2012). Thus, membrane protein integration can be reproduced by introducing lipid components such as DAG and MPlase into reconstituted proteoliposomes.

Recently, we found another problem when reconstituting proteoliposomes. DAG is not only solubilized by a series of detergents such as dodecyl maltoside (DDM) and dodecyl phosphocholine (DPC), but also forms wax-like complexes with them (Sasaki et al., 2019). Since these wax-like complexes induce the spontaneous integration, the detergents must be removed completely from the reconstituted proteoliposomes. On the other hand, DDM and DPC are frequently used to purify the SecYEG complex (Collinson et al., 2001) and YidC (Stiegler et al., 2011; Welte et al., 2012). Therefore, the membrane components should be properly reconstituted without the formation of the unexpected complexes that induce spontaneous integration.

In this protocol, we report a method for reconstituting proteoliposomes containing SecYEG and YidC, but free of the complex of DAG and DDM/DPC. To achieve this, SecYEG and/or YidC were first reconstituted into DAG-free proteoliposomes, followed by membrane fusion with liposomes containing DAG and MPlase by freezing-thawing-sonication, which yielded unilamellar proteoliposomes (Sasaki et al., 2019). Such proteoliposomes are ready for the membrane integration assay. This assay system includes a Pure System, a reconstituted translation system, to in vitro synthesize substrate membrane proteins (Nishiyama et al., 2010; Shimizu et al., 2001). The integration activity was determined by analyzing the membrane protected fragments (MPF) (Koch et al., 1999). The MPFs generated upon protease digestion after the integration reaction reflect the membrane integration. 


\section{Materials and Reagents}

1. Plastic tubes (1.5 ml) (Greiner, catalog number: 616201)

2. Ultracentrifuge tubes (1.5 ml) (Beckman Coulter, catalog number: 357448)

3. Glass vials (2 ml) (AS ONE, catalog number: 9-852-01)

4. Dialysis tubes (Tokyo Garasu Kikai Co., Ltd, catalog number: 03272337)

5. E. coli polar lipid extract (phospholipids) (Avanti Polar Lipids, Inc., catalog number: 100600C)

6. 1,2-Dioleoyl-sn-glycerol (DAG) (Merck, catalog number: D0138)

7. 2-[4-(2-Hydroxyethyl)-1-piperazinyl]ethanesulfonic acid (HEPES) (Dojindo Laboratories, catalog number: 342-01375)

8. Dithiothreitol (Wako, catalog number: 048-29224)

9. Chloroform, Guaranteed Reagent (Wako, catalog number: 038-02606)

10. Acetone, Guaranteed Reagent (Wako, catalog number: 012-00343)

11. $n$-Octyl- $\beta$-D-glucopyranoside (OG) (Dojindo Laboratory, catalog number: O001)

12. $\left[{ }^{35}\right.$ S]-EXPRESS Protein Labeling Mix (PerkinElmer Inc, catalog number: NEG072)

13. Pure System (Gene Frontier, catalog number: PF001-0.25)

14. Proteinase K (Roche, catalog number: 03115879 001)

15. Trichloroacetic acid, Guaranteed Reagent (Wako, catalog number: 204-02405)

16. Acrylamide, Electrophoresis grade (Wako, catalog number: 011-08015)

17. $N, N$-Methylenebis(acrylamide), Electrophoresis grade (Wako, catalog number: 130-06031)

18. Sodium dodecyl sulfate (SDS), for Molecular Biology (Wako, catalog number: 194-13985)

19. 2-Amino-2-hydroxymethyl-1,3-propanediol (Tris), Guaranteed Reagent (Wako, catalog number: 207-06275)

20. $\mathrm{Na}_{2} \mathrm{HPO}_{4}$, Guaranteed Reagent (Wako, catalog number: 197-02865)

21. $\mathrm{NaH}_{2} \mathrm{PO}_{4}$, Guaranteed Reagent (Wako, catalog number: 192-02815)

22. Glycine, Guaranteed Reagent (Wako, catalog number: 077-00735)

23. Bromophenol Blue (Wako, catalog number: 021-02911)

24. $\beta$-Mercaptoethanol (Wako, catalog number:131-14572)

25. Glycerol, Guaranteed Reagent (Wako, catalog number: 075-00611)

26. Ffh, purified as described (Eisner et al., 2003)

27. FtsY, purified as described (Koch et al., 1999)

28. YidC, purified as described (Nishikawa et al., 2017)

29. SecYEG, purified as described (Moser et al., 2013)

30. MPlase, purified as described (Nishiyama et al., 2010 and 2012)

31. TALON Metal Affinity Resin (Clontech, catalog number: 635503)

32. Imaging plates (GE, BAS IP MS 2025 E, catalog number: 28-9564-75)

33. Buffer A (see Recipes)

34. OG stock (see Recipes)

35. Sodium phosphate buffer (pH 7.2) (see Recipes) 


\section{Equipment}

1. Bath-type sonicator (Branson, model: Bransonic 12)

2. Freeze-dryer (EYELA, model: FD-80)

3. Vacuum pump (ULVAC, model: GCD-051X)

4. Ultracentrifuge (Beckman Coulter, model: Optima TL)

5. Rotor (Beckman Coulter, model: TLA-55)

6. Incubator (Eppendorf, model: Thermomixer Comfort)

7. Phosphorimager (GE, model: Storm 820)

8. $-80^{\circ} \mathrm{C}$ freezer

\section{Software}

1. ImageQuant software (GE Healthcare)

\section{Procedure}

A. Preparation of proteoliposomes containing proteinaceous factors such as SecYEG and YidC

1. Place the phospholipid solution ( $25 \mathrm{mg} / \mathrm{ml}$ in chloroform) in a glass vial. For one reconstitution sample, use $200 \mu \mathrm{g}$ of phospholipids. Dry phospholipids up under a $\mathrm{N}_{2}$ gas stream until the bulk of chloroform is evaporated, and then place in a freeze-dryer under vacuum for $1 \mathrm{~h}$.

2. Suspend the phospholipids ( $200 \mu \mathrm{g} /$ one reconstitution sample) in buffer $\mathrm{A}$ ( $50 \mathrm{mM} \mathrm{HEPES}-\mathrm{KOH}$, $\mathrm{pH} 7.5,1 \mathrm{mM}$ dithiothreitol) at $10 \mathrm{mg} / \mathrm{ml}$, followed by bath-sonication (about $10 \mathrm{~s}$ ) to form liposomes until a slightly opaque suspension is obtained.

3. Solubilize liposomes thus prepared in $1.5 \%[\mathrm{w} / \mathrm{v}]$ OG in buffer $A$ by adding $15 \%[\mathrm{w} / \mathrm{v}]$ stock.

4. Mix the solubilized phospholipids $(200 \mu \mathrm{g})$ with SecYEG $(\sim 10 \mu \mathrm{g})$ and/or YidC $(\sim 10 \mu \mathrm{g})$ solubilized in $1.5 \%[\mathrm{w} / \mathrm{v}] \mathrm{OG}$. Adjust the volume to $\sim 100 \mu$, keeping the OG concentration at $1.5 \%[\mathrm{w} / \mathrm{v}]$. Incubate the mixture on ice for $20 \mathrm{~min}$.

5. Change the detergents used to solubilize SecYEG and YidC to OG, if they were solubilized in DDM or DPC. Apply the sample to a TALON column, and then wash with buffer containing $1.5 \%$ [w/v] OG, followed by elution with buffer containing $100 \mathrm{mM}$ imidazole. In the case of SecYEG, add $40 \%[\mathrm{w} / \mathrm{v}]$ glycerol to the buffer. Keep the DDM/DPC concentration as low as possible.

6. Dialyze the mixture against $500 \mathrm{ml}$ of buffer $\mathrm{A}$ at $4{ }^{\circ} \mathrm{C}$ for at least $3 \mathrm{~h}$ to form proteoliposomes by removing $O G$. The proteoliposome suspension becomes a bit turbid.

7. Add $0.9 \mathrm{ml}$ of buffer $\mathrm{A}$ to the dialyzed sample, followed by recovery of proteoliposomes by centrifugation $\left(170,000 \times g, 1 \mathrm{~h}, 4^{\circ} \mathrm{C}\right)$. Resuspend the pellets in $50 \mu \mathrm{l}$ of buffer $\mathrm{A}$.

8. Make proteoliposomes unilamellar by freezing (in liquid nitrogen)-thawing (at room temperature)-sonication ( 10 s) once. Make sure that the suspension is not heated when it is sonicated. 
9. Store frozen proteoliposomes at $-80^{\circ} \mathrm{C}$, if necessary, before thawing and sonication.

B. Preparation of liposomes containing DAG

1. Mix phospholipids ( $1 \mathrm{mg}$ ) and DAG $(0.05 \mathrm{mg})$, and dry the lipid mixture up as in Step A1.

2. Suspend the dried residue in buffer $A$ at $10 \mathrm{mg}$ phospholipids $/ \mathrm{ml}$, followed by bath-sonication $(\sim 10 \mathrm{~s})$.

C. Preparation of liposomes containing DAG and MPlase

1. Mix phospholipids and DAG in chloroform, and dry the mixture up, as described in Step B1. Typically, add DAG at $25 \%[\mathrm{w} / \mathrm{w}]$ to phospholipids.

2. Dissolve the mixture in solvent $C$ (chloroform/ethanol/water $=3 / 7 / 4$ ), and then mix with MPlase dissolved in solvent $\mathrm{C}$, typically at $25 \%[\mathrm{w} / \mathrm{w}]$ as to phospholipids.

3. Evaporate solvent $\mathrm{C}$ under a $\mathrm{N}_{2}$ stream and then under vacuum.

4. Suspend the dried residue in buffer $\mathrm{A}$ at $10 \mathrm{mg}$ phospholipids $/ \mathrm{ml}$, followed by bath-sonication $(\sim 10 \mathrm{~s})$.

D. Fusion of proteoliposomes with MPlase/DAG-liposomes to incorporate MPlase and DAG

1. Mix the proteoliposome suspension obtained in Procedure A with MPlase/DAG-liposomes (Procedure C), typically in the ratio of $4: 1$, which yields proteoliposomes containing $5 \%[\mathrm{w} / \mathrm{w}]$ DAG and $5 \%[\mathrm{w} / \mathrm{w}]$ MPlase.

2. Repeat the cycle of freezing (in liquid nitrogen)-thawing (at room temperature)-sonication ( 10 s) three times to allow liposome fusion. With this way, proteoliposomes containing SecYEG, YidC, and MPlase/DAG can be prepared.

E. Reactions for (3L-)Pf3 coat integration (Figure 1)

1. Translate in vitro the substrate proteins, Pf3 coat and the mutant 3L-Pf3 coat (Kiefer and Kuhn, 1999; Serek et al., 2004), using the Pure System, a reconstituted cell-free system for in vitro translation (Nishiyama et al., 2010; Shimizu et al., 2001). The reaction mixture of the Pure System $(20 \mu \mathrm{l})$ comprises $\left[{ }^{35} \mathrm{~S}\right]$ methionine $(2.5 \sim 10 \mathrm{MBq} / \mathrm{ml} ; 200 \mathrm{nM}$ ), plasmid DNA (pT7-3LPf3 or pT7-Pf3 [Kawashima et al., 2008; Serek et al., 2004]; 20 $\mu \mathrm{g} / \mathrm{ml}$ ), and (proteo)liposomes (0.4 mg phospholipids $/ \mathrm{ml}$ ) (Table 1). When a high level of synthesis is necessary, add cold methionine $(0.3 \mathrm{mM})$ to the mixture. Under these conditions, a $\sim 200$-fold increase in the synthesis level is observed. The Pure System is commercially available from Gene Frontier, but adjust the buffer system customly as described (Nishiyama et al., 2010). To avoid aggregation of proteoliposomes, make sure that the $\mathrm{Mg}$ concentration is $9 \mathrm{mM}$ or less, and that PEG and polyamines such as putrescine and spermidine are not contained in the reaction mixtures.

2. Allow the translation/integration reaction at $37^{\circ} \mathrm{C}$ for $30 \mathrm{~min}$.

3. Terminate the reaction by chilling on ice for $5 \mathrm{~min}$. Withdraw $3 \mu \mathrm{l}$ and $15 \mu \mathrm{l}$ of the mixture $(20 \mu \mathrm{l})$ into new tubes. 
4. Add $3 \mu \mathrm{l}$ of trichloroacetic acid $(10 \%[\mathrm{w} / \mathrm{v}])$ to an aliquot $(3 \mu \mathrm{l})$ to precipitate the synthesized proteins.

5. Mix an equal volume of proteinase $\mathrm{K}(1 \mathrm{mg} / \mathrm{ml})$ with another aliquot $(15 \mu \mathrm{l})$, and then incubate at $25^{\circ} \mathrm{C}$ for 25 min to generate MPF.

6. After proteinase $\mathrm{K}$ digestion, add $30 \mu \mathrm{l}$ of $10 \%[\mathrm{w} / \mathrm{v}]$ trichloroacetic acid, followed by incubation at $56{ }^{\circ} \mathrm{C}$ for $5 \mathrm{~min}$ to inactivate proteinase $\mathrm{K}$. Incubate on ice for at least $10 \mathrm{~min}$ to precipitate MPF.

7. Recover the precipitates (both Steps E4 and E6) by centrifugation (10,000 $\times \mathrm{g}$, for $5 \mathrm{~min}$ ), and then wash them with $100 \%$ acetone. After centrifugation $(10,000 \times \mathrm{g}$, for $5 \mathrm{~min})$, dry the precipitates up at room temperature for 20 30 min.

8. Solubilize the precipitates in $10 \mu \mathrm{l}$ of SDS sample loading buffer A, followed by boiling for $3 \mathrm{~min}$. The SDS sample loading buffer $A$ is composed of $25 \mathrm{mM}$ sodium phosphate $(\mathrm{pH} 7.2), 2.5 \%[\mathrm{w} / \mathrm{v}]$ SDS, 25\% [w/v] glycerol, 2.5\% [w/v] $\beta$-mercaptoethanol, and 0.0125\% [w/v] bromophenol blue.

9. Apply samples onto SDS-gels containing $6 \mathrm{M}$ urea as described in Nishiyama et al. (2006). The gel is composed of $12.5 \%[\mathrm{w} / \mathrm{v}]$ acrylamide- $0.27 \%[\mathrm{w} / \mathrm{v}] \mathrm{N}, \mathrm{N}$-methylenebis(acrylamide) in 100 mM sodium phosphate buffer (pH 7.2) as described in Hussain et al. (1980).

10. After electrophoresis, soak the gels in $10 \%[\mathrm{v} / \mathrm{v}]$ acetic acid for $10 \mathrm{~min}$, and then dry them.

11. Expose the gels to the imaging plates in a cassette overnight.

Table 1. Composition of the Pure System

\begin{tabular}{cl}
\hline $\begin{array}{c}\text { Energy sources } \\
2 \mathrm{mM}\end{array}$ & ATP, GTP \\
$1 \mathrm{mM}$ & CTP, UTP \\
$20 \mathrm{mM}$ & creatine phosphate \\
\hline Buffers & HEPES-KOH, pH 7.6 \\
$50 \mathrm{mM}$ & potassium glutamate \\
$100 \mathrm{mM}$ & magnesium acetate \\
$9 \mathrm{mM}$ & DTT \\
$1 \mathrm{mM}$ & \\
\hline Other components & 19 amino acids except for methionine \\
$0.3 \mathrm{mM}$ & 10 -formyl-5,6,7,8-tetrahydrofolic acid \\
$10 \mathrm{mg} / \mathrm{ml}$ & tRNAmix \\
$56 \mathrm{~A} 260 \mathrm{~nm} / \mathrm{ml}$ & Enzyme mix (1/20 dilution) \\
$1 \mu \mathrm{M}$ & ribosomes \\
\hline$\sim 20 \mu \mathrm{g} / \mathrm{ml}$ & plasmid DNA \\
$\sim 200 \mathrm{nM}$ & {$\left[{ }^{35}\right.$ S] methionine } \\
$0.4 \mathrm{mg} / \mathrm{ml}$ & (proteo)liposomes \\
\hline
\end{tabular}




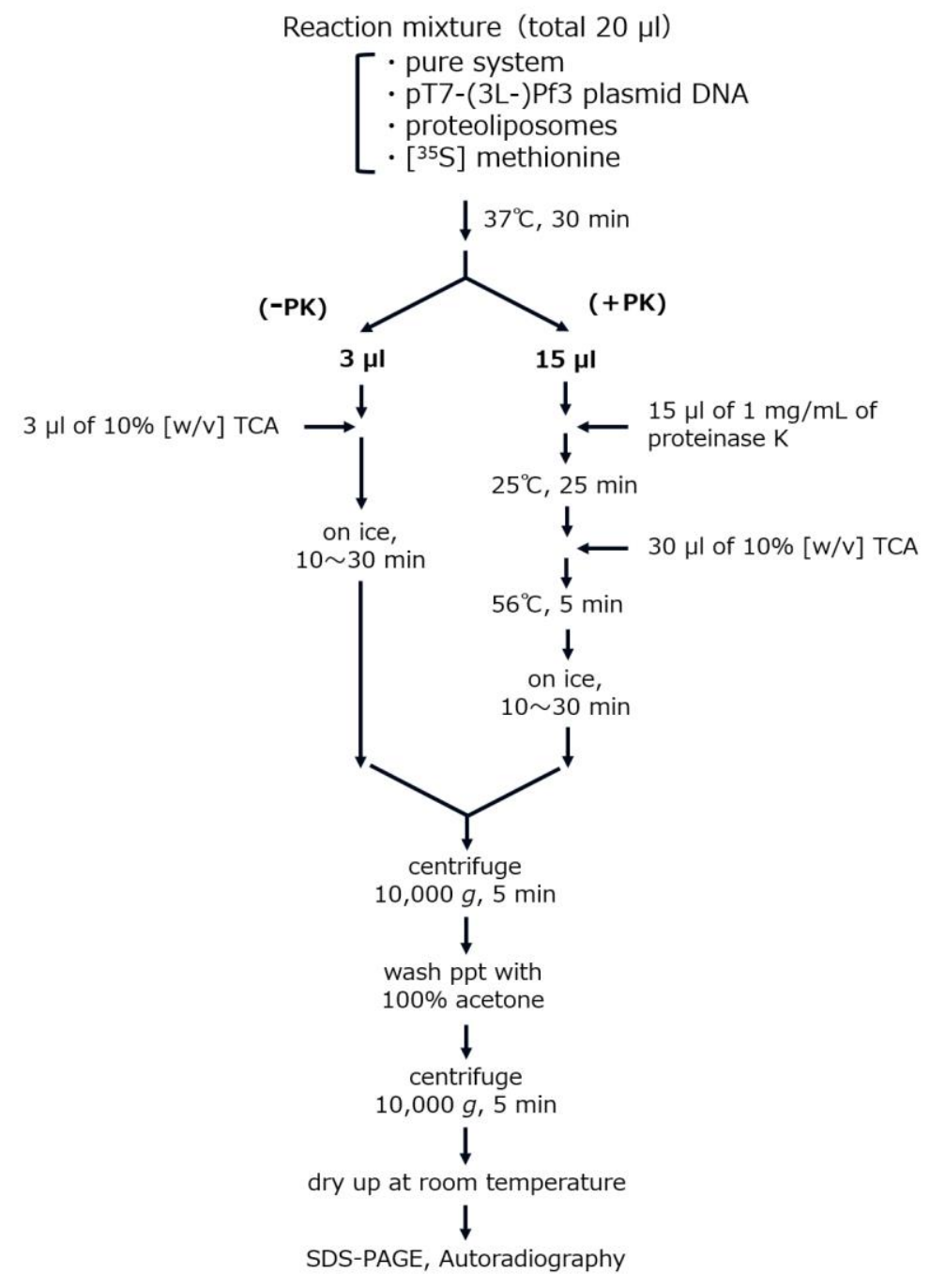

Figure 1. Scheme of the assay for (3L-)Pf3 coat integration

F. Reactions for MtIA (mannitol permease) integration

1. Synthesize MtIA as in E, using pET-MtIA (Kuruma et al., 2005) and the Pure System. Add Ffh $(50 \mu \mathrm{g} / \mathrm{ml})$, FtsY $(17 \mu \mathrm{g} / \mathrm{ml})$, and cold methionine $(30 \mu \mathrm{M})$ to the reaction mixture.

2. After the translation/integration reaction at $37^{\circ} \mathrm{C}$ for $30 \mathrm{~min}$, add $5 \%[\mathrm{w} / \mathrm{v}]$ trichloroacetic acid to an aliquot $(9 \mu \mathrm{l})$, and digest another aliquot $(9 \mu \mathrm{l})$ with proteinase $\mathrm{K}$ as described in Steps E4E5. Recover the precipitate as described in Step E5.

3. Solubilize the dried precipitates in $10 \mu \mathrm{l}$ of SDS sample loading buffer $B$, followed by boiling for $3 \mathrm{~min}$. The SDS sample loading buffer $\mathrm{B}$ is composed of $62.5 \mathrm{mM}$ Tris- $\mathrm{HCl}(\mathrm{pH} \mathrm{6.8)}, 3 \%$ [w/v] SDS, $10 \%[\mathrm{w} / \mathrm{v}]$ glycerol, $5.5 \%[\mathrm{w} / \mathrm{v}] \beta$-mercaptoethanol, and $0.01 \%[\mathrm{w} / \mathrm{v}]$ bromophenol blue.

4. Load samples onto SDS-gels as described (Laemmli, 1970). The gel is composed of $15 \%$ [w/v] acrylamide- $0.4 \%[\mathrm{w} / \mathrm{v}] \mathrm{N}, \mathrm{N}$-methylenebis(acrylamide).

5. After electrophoresis, soak gels in $10 \%[\mathrm{v} / \mathrm{v}]$ acetic acid for $10 \mathrm{~min}$, and then dry them. Place the gels on the imaging plates. 


\section{Data analysis}

Determination of the integration activity

1. Detect radioactive bands of the synthesized substrates and MPF using a Phosphorimager.

2. Determine the radioactivity of each band using the ImageQuant software (Figure 2). Subtract the background level manually with the software.

3. Determine the integration activities by dividing the MPF level with that of the synthesized substrate (Figure 2, bottom of each gel image). Consider the numbers of methionine in substrates and MPF.

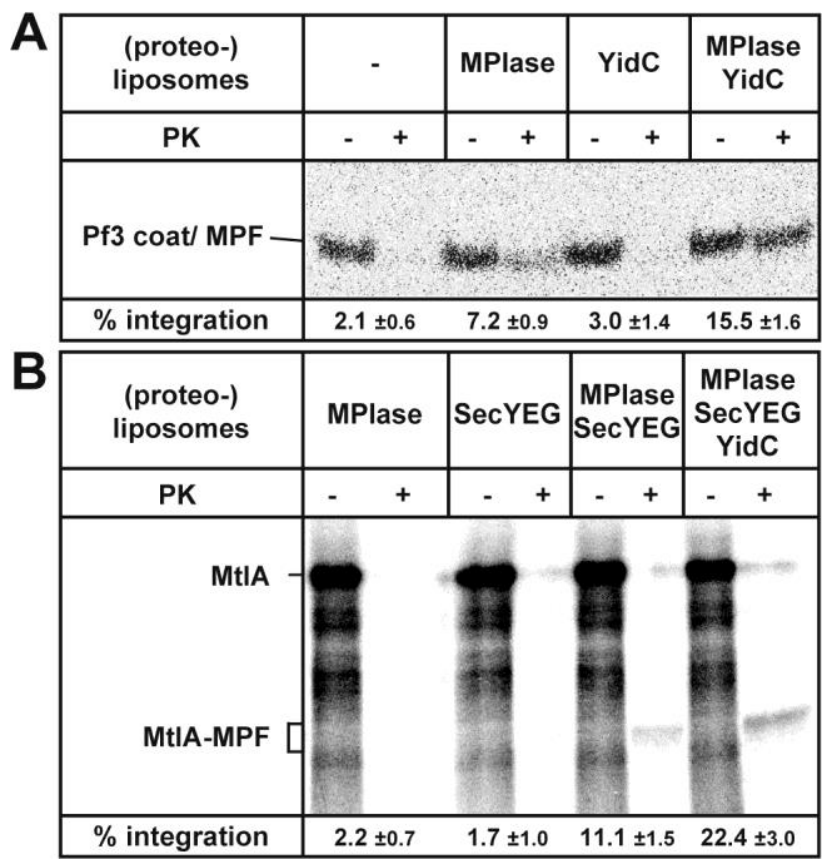

Figure 2. Examples of the results of the integration assay. A. Pf 3 coat integration depends on MPlase and is stimulated by YidC. B. Both MPlase and SecYEG are essential for MtIA integration. Moreover, YidC stimulates the MPlase/SecYEG-dependent integration of MtIA. The numbers of methionine ( 25 for MtIA and 18 for MtIA-MPF) were taken into account for activity determination. Images were taken from Sasaki et al., 2019 (Figures 3C and 3D).

\section{Recipes}

1. Buffer $A$

Dilute $1 \mathrm{M}$ HEPES-KOH $(\mathrm{pH} \mathrm{7.2)}$ and $1 \mathrm{M}$ dithiothreitol solutions to $50 \mathrm{mM}$ and $1 \mathrm{mM}$, respectively, with $\mathrm{dd}_{2} \mathrm{O}$

2. OG stock

Dissolve $\mathrm{OG}$ in $\mathrm{ddH}_{2} \mathrm{O}$ at $15 \%[\mathrm{w} / \mathrm{v}]$, and store at $4{ }^{\circ} \mathrm{C}$

3. Sodium phosphate buffer ( $\mathrm{pH} 7.2)$ 
Please cite this article as: Nishikawa et. al., (2020). In vitro Assay for Bacterial Membrane Protein Integration into Proteoliposomes,Bio-protocol 10 (10):
a. Prepare $1 \mathrm{M} \mathrm{NaH}_{2} \mathrm{PO}_{4}$ and $1 \mathrm{M} \mathrm{Na}_{2} \mathrm{HPO}_{4}$ solutions
b. Mix these, monitoring the $\mathrm{pH}$, to yield $1 \mathrm{M}$ sodium phosphate buffer $(\mathrm{pH} 7.2)$
c. Stock this solution at room temperature

\section{Acknowledgments}

This work was supported by Japan Society for the Promotion of Science Grants-in-Aid 18J21847 (to H. N.); 15KT0073, 16H01374, 16K15083, $17 \mathrm{H} 02209$ and 18KK0197 (to K. N.). This protocol was derived from our report (Sasaki et al., 2019).

\section{Competing interests}

We declare that we have no competing interests.

\section{References}

1. Alami, M., Trescher, D., Wu, L. F. and Muller, M. (2002). Separate analysis of twin-arginine translocation (Tat)-specific membrane binding and translocation in Escherichia coli. J Biol Chem 277(23): 20499-20503.

2. Collinson, I., Breyton, C., Duong, F., Tziatzios, C., Schubert, D., Or, E., Rapoport, T. and Kuhlbrandt, W. (2001). Projection structure and oligomeric properties of a bacterial core protein translocase. Embo J 20(10): 2462-2471.

3. Eisner, G., Koch, H. G., Beck, K., Brunner, J. and Muller, M. (2003). Ligand crowding at a nascent signal sequence. J Cell Biol 163(1): 35-44.

4. Hussain, M., Ichihara, S. and Mizushima, S. (1980). Accumulation of glyceride-containing precursor of the outer membrane lipoprotein in the cytoplasmic membrane of Escherichia coli treated with globomycin. J Biol Chem 255(8): 3707-3712.

5. Kawashima, Y., Miyazaki, E., Muller, M., Tokuda, H. and Nishiyama, K. (2008). Diacylglycerol specifically blocks spontaneous integration of membrane proteins and allows detection of a factor-assisted integration. J Biol Chem 283(36): 24489-24496.

6. Kiefer, D. and Kuhn, A. (1999). Hydrophobic forces drive spontaneous membrane insertion of the bacteriophage Pf3 coat protein without topological control. EMBO J 18(22): 6299-6306.

7. Koch, H. G., Hengelage, T., Neumann-Haefelin, C., MacFarlane, J., Hoffschulte, H. K., Schimz, K. L., Mechler, B. and Muller, M. (1999). In vitro studies with purified components reveal signal recognition particle (SRP) and SecA/SecB as constituents of two independent protein-targeting pathways of Escherichia coli. Mol Biol Cell 10(7): 2163-2173.

8. Koch, H. G. and Muller, M. (2000). Dissecting the translocase and integrase functions of the Escherichia coli SecYEG translocon. J Cell Biol 150(3): 689-694. 
Please cite this article as: Nishikawa et. al., (2020). In vitro Assay for Bacterial Membrane Protein Integration into Proteoliposomes,Bio-protocol 10 (10):

9. Kuruma, Y., Nishiyama, K., Shimizu, Y., Muller, M. and Ueda, T. (2005). Development of a minimal cell-free translation system for the synthesis of presecretory and integral membrane proteins. Biotechnol Prog 21(4): 1243-1251.

10. Laemmli, U. K. (1970). Cleavage of structural proteins during the assembly of the head of bacteriophage T4. Nature 227(5259): 680-685.

11. Moser, M., Nagamori, S., Huber, M., Tokuda, H. and Nishiyama, K. (2013). Glycolipozyme MPlase is essential for topology inversion of SecG during preprotein translocation. Proc Natl Acad Sci U S A 110(24): 9734-9739.

12. Newitt, J. A. and Bernstein, H. D. (1998). A mutation in the Escherichia coli secY gene that produces distinct effects on inner membrane protein insertion and protein export. $J$ Biol Chem 273(20): 12451-12456.

13. Nishikawa, H., Sasaki, M. and Nishiyama, K. (2017). Membrane insertion of $F_{0} c$ subunit of $F_{0} F_{1}$ ATPase depends on glycolipozyme MPlase and is stimulated by YidC. Biochem Biophys Res Commun 487(2): 477-482.

14. Nishiyama, K., Ikegami, A., Moser, M., Schiltz, E., Tokuda, H. and Muller, M. (2006). A derivative of lipid $A$ is involved in signal recognition particle/SecYEG-dependent and -independent membrane integrations. J Biol Chem 281(47): 35667-35676.

15. Nishiyama, K., Maeda, M., Abe, M., Kanamori, T., Shimamoto, K., Kusumoto, S., Ueda, T. and Tokuda, H. (2010). A novel complete reconstitution system for membrane integration of the simplest membrane protein. Biochem Biophys Res Commun 394(3): 733-736.

16. Nishiyama, K., Maeda, M., Yanagisawa, K., Nagase, R., Komura, H., Iwashita, T., Yamagaki, T., Kusumoto, S., Tokuda, H. and Shimamoto, K. (2012). MPlase is a glycolipozyme essential for membrane protein integration. Nat Commun 3: 1260.

17. Samuelson, J. C., Chen, M., Jiang, F., Moller, I., Wiedmann, M., Kuhn, A., Phillips, G. J. and Dalbey, R. E. (2000). YidC mediates membrane protein insertion in bacteria. Nature 406(6796): 637-641.

18. Sasaki, M., Nishikawa, H., Suzuki, S., Moser, M., Huber, M., Sawasato, K., Matsubayashi, H. T., Kumazaki, K., Tsukazaki, T., Kuruma, Y., Nureki, O., Ueda, T. and Nishiyama, K. I. (2019). The bacterial protein YidC accelerates MPlase-dependent integration of membrane proteins. $J$ Biol Chem 294(49): 18898-18908.

19. Serek, J., Bauer-Manz, G., Struhalla, G., van den Berg, L., Kiefer, D., Dalbey, R. and Kuhn, A. (2004). Escherichia coli YidC is a membrane insertase for Sec-independent proteins. EMBO J 23(2): 294-301.

20. Shimizu, Y., Inoue, A., Tomari, Y., Suzuki, T., Yokogawa, T., Nishikawa, K. and Ueda, T. (2001). Cell-free translation reconstituted with purified components. Nat Biotechnol 19(8): 751-755.

21. Stiegler, N., Dalbey, R. E. and Kuhn, A. (2011). M13 procoat protein insertion into YidC and SecYEG proteoliposomes and liposomes. J Mol Biol 406(3): 362-370.

22. Ulbrandt, N. D., Newitt, J. A. and Bernstein, H. D. (1997). The E. coli signal recognition particle is required for the insertion of a subset of inner membrane proteins. Cell 88(2): 187-196. 
23. Welte, T., Kudva, R., Kuhn, P., Sturm, L., Braig, D., Muller, M., Warscheid, B., Drepper, F. and Koch, H. G. (2012). Promiscuous targeting of polytopic membrane proteins to SecYEG or YidC by the Escherichia coli signal recognition particle. Mol Biol Cell 23(3): 464-479. 